\title{
Scaffold attachment factor B1 directly interacts with nuclear receptors in living cells and represses transcriptional activity
}

\author{
M-B Debril', L Dubuquoy', J-N Feige², W Wahli², B Desvergne², J Auwerx' \\ and L Gelman ${ }^{1,2}$ \\ ${ }^{1}$ Institut de Génétique et de Biologie Moléculaire et Cellulaire (IGBMC), CNRS / INSERM / ULP, BP10142, 67404 Illkirch Cedex, France \\ ${ }^{2}$ Center for Integrative Genomics, NCCR Frontiers in Genetics, University of Lausanne, 1015 Lausanne, Switzerland
}

(Requests for offprints should be addressed to J Auwerx; Email: auwerx@igbmc.u-strasbg.fr)

\begin{abstract}
Transcriptional activity relies on coregulators that modify the chromatin structure and serve as bridging factors between transcription factors and the basal transcription machinery. Using the DE domain of human peroxisome proliferator-activated receptor gamma (PPAR $\gamma$ ) as bait in a yeast two-hybrid screen of a human adipose tissue library, we isolated the scaffold attachment factor B1 (SAFB1/HET/HAP), which was previously shown to be a corepressor of estrogen receptor $\alpha$. We show here that SAFB1 has a very broad tissue expression profile in human and is also expressed all along mouse embryogenesis. SAFB1 interacts in pull-down assays not only with PPAR $\gamma$ but also with all nuclear receptors tested so far, albeit with different affinities. The association of SAFB1 and PPAR $\gamma$ in vivo is further demonstrated by fluorescence resonance energy transfer (FRET) experiments in living cells. We finally show that SAFB1 is a rather general corepressor for nuclear receptors. Its change in expression during the early phases of adipocyte and enterocyte differentiation suggests that SAFB1 potentially influences cell proliferation and differentiation decisions.
\end{abstract}

Journal of Molecular Endocrinology (2005) 35, 503-517

\section{Introduction}

In eukaryotic cells, the structure of chromatin has been shown to repress mainly gene activation, and both remodeling and repositioning of nucleosomes are necessary to allow binding of transcription factors and the formation of the transcriptional preinitiation complex (Horn \& Peterson 2002). Chromatin-modifying complexes have been classified into two main groups. The first one comprises factors which covalently modify histone tails (Chen et al. 1999, Roth et al. 2001, Wang et al. 2001, Bauer et al. 2002). The second group of chromatin modifiers comprises complexes that change the location or conformation of nucleosomes and remodel chromatin by using energy from ATP hydrolysis (Sudarsanam \& Winston 2000, Becker \& Horz 2002, Neely \& Workman 2002).

The peroxisome proliferator-activated receptor gamma (PPAR $\gamma$ or NR1C3) is one of the three PPARs, which together constitute a distinct subfamily of the nuclear receptors. PPAR $\gamma$ has mostly been studied because of its key role in adipocyte differentiation, where it acts as a master controller of the 'thrifty gene response' (Auwerx 1999, Rosen \& Spiegelman 2001), but it has many additional functions (Debril et al. 2001). PPAR $\gamma$ heterodimerizes with the retinoid $\mathrm{X}$ receptors (RXRs) and is activated by naturally occurring fatty acids or fatty acid derivatives (Schoonjans et al. 1997). In addition to these natural PPAR $\gamma$ ligands, several classes of synthetic PPAR $\gamma$ agonists have been described, including the thiazolidinediones, which are potent insulin sensitizers used in the treatment of type 2 diabetes mellitus (Schoonjans \& Auwerx 2000, Willson et al. 2001). In order to modulate gene transcription, PPARs, like most transcription factors, rely on coregulators that modify chromatin (Robyr et al. 2000, Urnov \& Wolffe 2001). Coregulators partially determine the specificity of action of nuclear receptors and integrate their different activities to orchestrate a specific cellular response.

The aim of the study was to identify novel PPAR $\gamma$-interacting proteins that could influence the activity of this nuclear receptor. We characterized here a new coregulator isolated from human adipose tissue with a yeast two-hybrid screen, with the DE domain of $\operatorname{PPAR} \gamma$ as bait (including the ligand-binding domain). This regulator is known as SAFB1/HET/HAP (scaffold attachment factor B1/heat-shock protein 27 estrogen response element TATA (hsp27 ERE TATA)binding protein/heterogeneous nuclear ribonucleoprotein (hnRNP) Al-associated protein). The nuclear protein SAFB 1 was initially identified independently by three groups as a scaffold/matrix attachment region (S/MAR)-binding protein (Renz \& Fackelmayer 1996), binding to an ERE flanking a TATA box in the 
promoter of the hsp27 (Oesterreich et al. 1997), and as a partner of hnRNP Al (Weighardt et al. 1999). Additionally, it was shown to bind to the C-terminal domain of RNA polymerase II (RNA Pol II) and to certain serine/ arginine-rich RNA-processing factors (SR proteins) and hence to have a role in mRNA splicing (Nayler et al. 1998). This protein functions as an ER $\alpha$ corepressor (Oesterreich et al. 2000), and represses cell proliferation (Townson et al. 2000). Hence, a role for SAFB1 in tumor development has been suggested (reviewed in Oesterreich 2003). Recently, a second SAFB gene, SAFB2, has been described (Townson et al. 2003). Both genes are arranged in head-to-head orientation on the same chromosome. They are separated by a region that functions as a bidirectional promoter (Townson et al. 2003). We show here that SAFB1 binds in fact to multiple nuclear receptors, mostly in a ligand-independent manner, and inhibits their transcriptional activity. This suggests that SAFB1 is a general corepressor for nuclear receptors. Furthermore, SAFB1 expression level is modified during adipocyte differentiation of 3T3-L1 preadipocytes and enterocyte differentiation of Caco-2 cells. SAFB1 might hence be involved in cell proliferation and differentiation choices.

\section{Materials and methods}

\section{Materials}

Rosiglitazone and GW4064 were gifts of R Heyman (X-ceptor, San Diego, CA, USA). Wy14 643 compound was purchased from Cayman Chemical Co. (Ann Arbor, MI, USA), and the L-165041 compound was synthesized in the laboratory by Marco Alves. All chemicals, unless stated otherwise, were purchased from Sigma. Suberoylanilide hydroxamic acid (SAHA) was purchased from Biomol (Buttler Pike, PA, USA), and MS-275 was from Calbiochem (San Diego, CA, USA).

\section{Plasmids}

hSAFB 1 full-length cDNA was obtained by a two-step PCR amplification. First, SAFB1 N-terminus was amplified from IMAGE clone 4999249 (UK HGMP Resource Center, Cambridge, UK) with 5'-gTC gAg ggA CCg AAC ggA CTg Tag-3' and 5'-CGg gAA TTC Cgg TCA gTA gCg gCg AgT gAA gCg-3' and from $\mathrm{SAFB} 1 \mathrm{C}$-terminus (our clone no. 66, isolated by yeast two-hybrid screening) with 5'-CgC ggA TCG gCg gTC CGT ggA ATg gCg gAg ACT CTg-3' and 5'-CTA CAg TCG gTT Cgg TCG CTG gAC-3'. The full-length cDNA was then amplified from these two fragments with the external primers and inserted into $\mathrm{pBS}(\mathrm{SK}+)$ (Stratagene, La Jolla, CA, USA). This cDNA was then introduced into the expression vector pSG5 (Stratagene). pSG5-SAFB-HA, containing the hSAFB1 C-terminus (aa 532-915) fused to HA tag, was a kind gift of S Kato
(Arao et al. 2000). hSAFBl and mPPAR $\gamma 1$ were cloned after PCR amplification in pEYFP-C1 and pECFP-C1 using Sal I/BamHI and XhoI/KpnI restriction sites respectively. pSG5-mFXR $\alpha$ was obtained by PGR amplification of mFXR from liver cDNA, using the primers 5'-A CgC ggA TCC Agg ATg gTg ATg CAg TTT CAg gg-3' and 5'-CgC gCT AgC CAA CTg gTg TCG ATC ACT gC-3'. The primers introduce a BamHI site (underlined). The PCR product was cloned into pSG5, using the BamHI site and a blunted BglII site. The luciferase reporter construct for FXR $\alpha$ contains the $-496 /+40$ part of mouse intestinal bile acid-binding protein promoter and is a kind gift of D Mangelsdorf. pGMX-hROR $\alpha 1$, pSG5-hPPAR $\gamma 2$, pCMX-hLRH-1, pSG5-mSF1, pSG5-hcJun (a gift of P Sassone Corsi) and pSG5-hVDR (a gift from S Kato) are expression vectors used for in vitro translation and/or transfection. pGL3-J3TK-Luc (luciferase construct with a PPAR response element), pcDNA3-BDGal4-hPPAR $\gamma$ DE (amino acids (aa) 181-507) and pGL3-(GAL5)-TK-Luc reporter plasmids were already described (Debril et al. 2004). pGL3-RORE(3)-TKLuc was a gift from V Giguere. pCMV- $\beta$ Gal was used as a control of transfection efficiency. hSAFBl cDNA was subcloned into pLPCX (Clontech) for retroviral experiments. The mouse PPAR $\alpha$ and mouse PPAR $\beta$ expression vectors were kind gifts of Drs Green and Grimaldi respectively.

\section{Construction of the yeast two-hybrid library and screening}

Adipose tissue was obtained from a female nonobese adult subject undergoing endoscopic cholecystectomy after informed consent was obtained. The local ethics committee of the Centre Hospitalier Universitaire in Lille, France, approved the project. cDNA library preparation, library screening and prey construct purification, were done according to the manufacturer (Stratagene). To create the bait vector, the DE domains of PPAR $\gamma 2$ (residues 179-505) were cloned downstream of the DNA-binding domain of Gal4. YRG-2 yeast (Stratagene) was sequentially transformed, with the bait construct and with the library, and grown on the appropriate selective medium in the presence of the PPAR $\gamma$ ligand rosiglitazone $(1 \mu \mathrm{M})$. About $5 \cdot 10^{6}$ cotransformants were obtained. The first 100 clones which grew on the selective medium were selected for prey construct purification and sequencing.

\section{RNA isolation, RT-PCR and quantitative PCR, oligonucleotides}

RNA was isolated from cell lines and embryos by the acid guanidinium thiocyanate/phenol/chloroform method (Chomczynski \& Sacchi 1987). RNAs from human tissues were purchased at Clontech (human total 
RNA master panel II). Reverse transcription (RT) of RNA was performed as described (Fayard et al. 2003). Quantitative real-time PGRs (Q-PGRs) were performed with a LightCycler and the DNA double-strand specific SYBR Green I dye for detection (Roche). The oligonucleotides used are as follows: 5'-CTG TGG TAG GAA TTT CTG GG-3' and 5'-AA TGT CGA GCG GGT CTC GCT-3' for SAFB1, and 5'-ATG GGT GAA ACT CTG GGA GAT TCT-3' and 5'-CTT GGA GCT TCA GGT CAT ATT TGT A -3' for PPAR $\gamma 2$.

\section{Cell culture, transfections, retroviral overexpression}

Cell lines were maintained at $37^{\circ} \mathrm{C}, 5 \% \mathrm{CO}_{2}$ according to the supplier's instructions (ATCG, Manassas, VA, USA). Cells were transfected with lipofectamine (Life Technologies, Burlington, Canada) in 48-well plates. Empty expression vectors were used to maintain equivalent amounts of DNA in the transfections. Luciferase and $\beta$-galactosidase activities were measured as described (Gelman et al. 1999). Histograms on figures 5 and 6 represent the mean of three independent experiments, in which each point was performed in triplicate. Retroviral overexpression was performed as previously described (Debril et al. 2004).

\section{Adipocyte and enterocyte differentiation}

Differentiation of 3T3-L1 cells into adipocytes was performed as described (Debril et al. 2004). Briefly, proliferating 3T3-L1 cells (day 2) are grown to confluence (day 0 ). Cells are then treated with the differentiation mix for 2 days. Medium is then changed every other day with a medium containing insulin. The differentiation starts with a clonal expansion phase, during which cells re-enter cell cycle, followed by an accumulation of lipids during terminal adipocyte differentiation. For enterocyte differentiation, proliferating Caco-2 cells (day 1) are grown to confluence and maintained for 21 days after confluence. Culture medium was changed every other day.

\section{Protein production, pull-down assays, immunoblotting}

For glutathione S-transferase (GST) pull-down assays, SAFB 1 full-length protein and deletion mutants of PPAR $\gamma$ (PPAR $\gamma \mathrm{AB}$, aa 31-129; PPAR $\gamma \mathrm{bABC}$, aa 1-211; and PPAR $\gamma$ DE, aa 204-507, a kind gift from G Zhou) and p300 (p300Nt: aa 2-516) were subcloned downstream of the GST cDNA in the pGex-4T1 vector (Pharmacia, Orsay, France). The GST fusion proteins were prepared as described (Gelman et al. 1999). Pull-down assays were performed with in vitro ${ }^{35} \mathrm{~S}$-labeled translated proteins (TNT Quick Rabbit Reticulocyte; Promega) as described (Gelman et al. 1999). Ligand was added when indicated. Immunoblotting was performed as described (Gelman et al. 1999). Antibodies directed against SAFB (Upstate, Lake Placid, NY, USA), PPAR $\gamma$ (Santa Cruz. Heidelberg, Germany) and actin (Santa Cruz) were used at the following dilutions: 1:500, 1:1000 and 1:5000 respectively.

\section{Confocal imaging}

Live cells on LabTek chambered cover glasses were washed once with phenol red free Optimem medium (Gibco) containing ligands or their vehicles and observed in the same medium. Observations were performed at $37^{\circ} \mathrm{C}$ on a TCS SP2 AOBS confocal microscope (Leica, Wetzlar, Germany) equipped with a whole-microscope incubator (Life Imaging Service, Reinach, Switzerland). Acquisitions were performed with a 63/NA 1.2 water immersion objective. Observation of EYFP fusion proteins was done by exciting at $514 \mathrm{~nm}$ and detecting emission at 525-575 nm.

\section{Fluorescence resonance energy transfer (FRET) experiments}

Transfections were performed as described above, but expression levels of donor and acceptor proteins were adjusted to similar levels by western blot. Fluorescence was recorded in three different settings: GFPex: $405 \mathrm{~nm} /$ CFPem: 465-485 nm; YFPex: $514 \mathrm{~nm} / Y F P e m: ~ 525-$ $545 \mathrm{~nm}$; and FRETex: $405 \mathrm{~nm} /$ FRETem: 525-545 nm. Laser power and detector gain were adjusted in the different channels in order to observe equimolar concentrations of CFP and YFP at equal intensities (equimolar concentrations of CFP and YFP were obtained by expressing a fusion protein of CFP and YFP spaced by 475 residues). Settings were kept unchanged for analysis of all samples, and background-corrected 8-bit images were quantified by measuring the average intensity of a region of interest, using the Leica Confocal Software (LCS), Version 2.4. CFP and YFP spectral bleedthroughs (BT) in the FRET setting were determined on cells expressing CFP or YFP alone by fitting the intensity ratios IFRET/ICFP and IFRET/IYFP to an exponential model (Feige et al. 2005). FRET measured in coexpressing cells was then corrected for spectral bleed-throughs and normalized (NFRET) for expression levels according to the following formula (Xia \& Liu 2001):

$$
\text { NFRET }=\frac{I_{F R E T}-I_{C F P} * B T_{C F P}-I_{Y F P} * B T_{Y F P}}{\sqrt{I_{C F P} * I_{Y F P}}}
$$

\section{Results}

\section{Isolation of SAFB1, a ubiquitously expressed protein}

PPAR $\gamma$ is highly expressed in adipose tissue, where its function has been well characterized (Cock et al. 2004). 
A

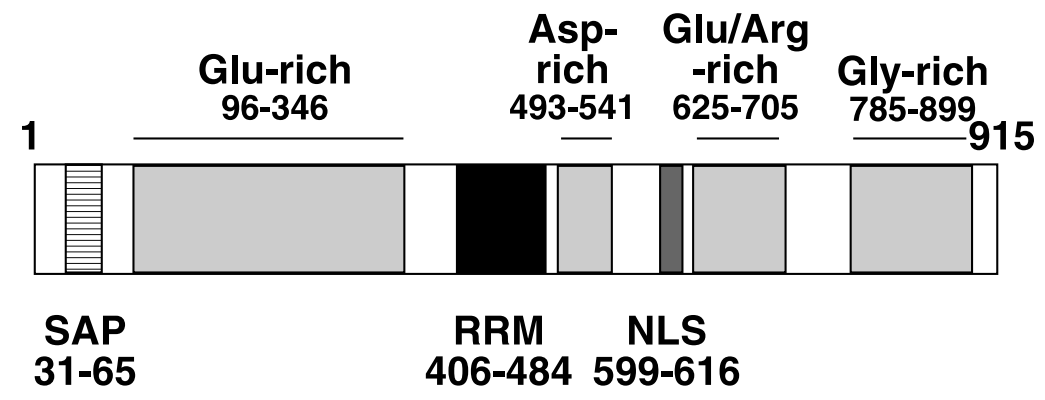

421

915

clone \#66

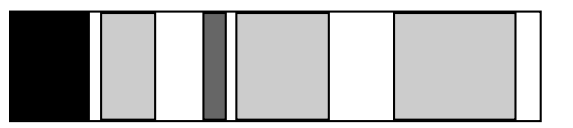

B

Human tissues

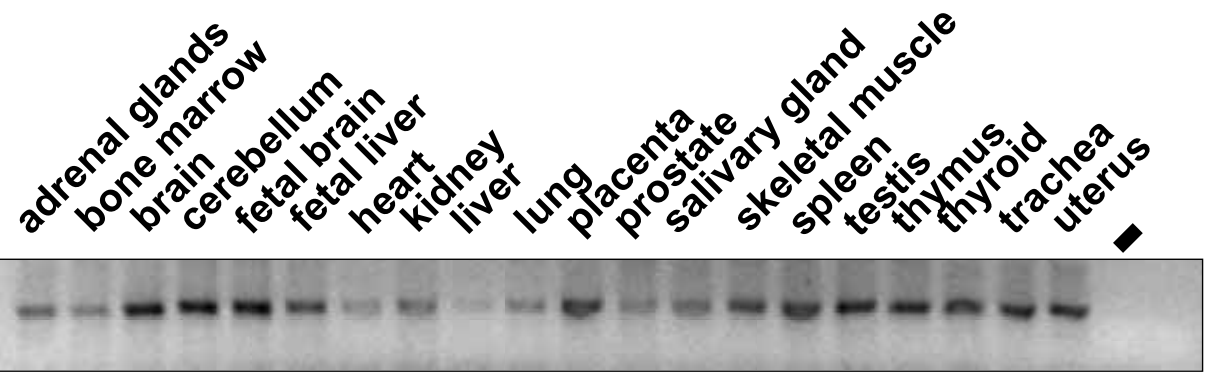

SAFB

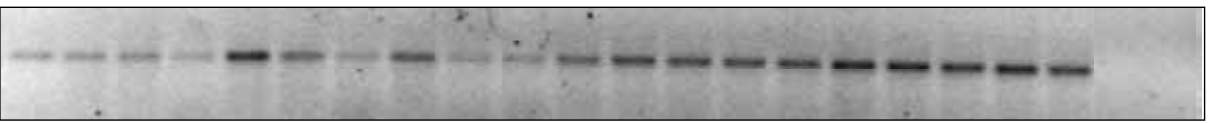

36B4

C Mouse embryos

$\begin{array}{llllll}6 & 9.5 & 11.5 & 13.5 & 16 & 19\end{array}$

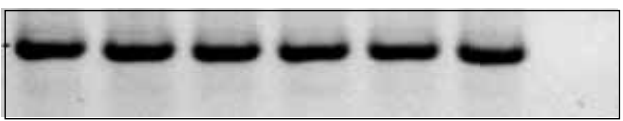

SAFB

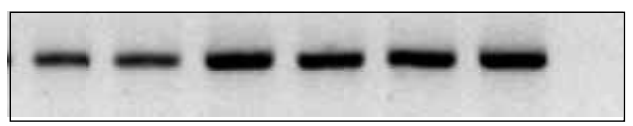

36B4

Figure 1 SAFB1 structure and mRNA expression. (A) SAFB1 and clone no. 66 secondary structures. SAFB1 is a large protein of 915 amino acids. It possesses an N-terminal SAF box also called SAP domain (hatched box), a central RNA recognition motif (RRM, black box) and a nuclear localization signal (NLS, dark gray). SAFB1 also contains some regions rich in the indicated amino acids (light gray boxes), which might be important for protein-protein interactions. Clone no. 66 was isolated by yeast two-hybrid screening. It corresponds to the C-terminal part of SAFB1 (amino acids 421-915). Amino-acid numbering was added on the figure to define the described domains. (B and C) SAFB1 mRNA expression was analyzed by RT-PCR. 36B4 is used as the internal control. SAFB1 mRNA is ubiquitously expressed in various human tissues. Negative control of PCR is indicated by (-) (B). SAFB1 mRNA is expressed early during mouse embryo development $(C)$. Numbers in $C$ indicate the number of days since fecondation. 
A

\section{human PPAR $\mathbf{2}$}

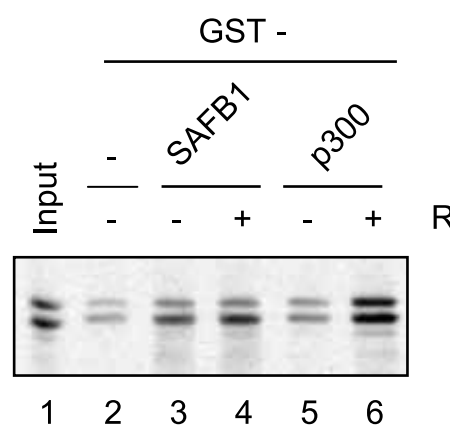

mouse PPAR $\gamma 1$

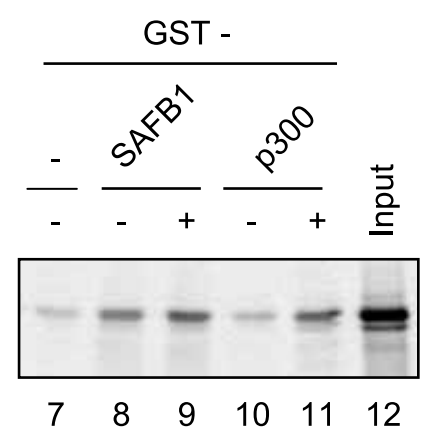

B

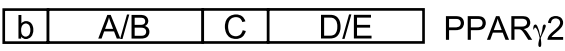

GST D/E

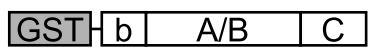

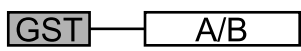

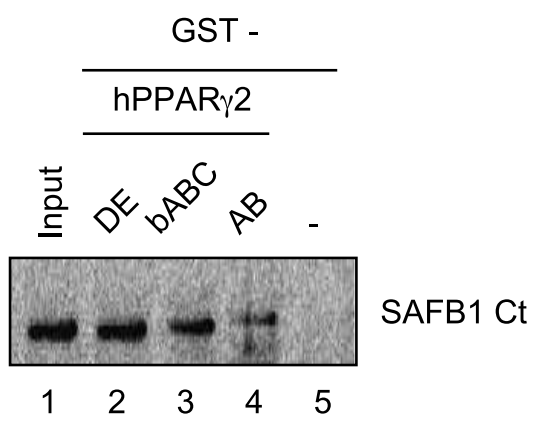

Figure 2 SAFB1 interacts with some nuclear receptors PPAR $\gamma$ in vitro. (A) In vitro translated PPAR $\gamma$ was incubated with GST-SAFB1, GST-p300 or GST alone, in the presence or absence of ligand (rosiglitazone, $10^{-5} \mathrm{M}$ ). PPAR $\gamma$ was detected by autoradiography. (B) Various domains of hPPAR $\gamma 2$ were incubated with the SAFB1 C-terminus fused to HA. A scheme of the various GST-PPAR $\gamma$ proteins used is provided on top left of the panel. The SAFB1-HA bound protein was detected with an anti-HA antibody.

To isolate new PPAR $\gamma$ coregulators, we performed a yeast two-hybrid screen of a human adipose tissue cDNA library with the DE domains of PPAR $\gamma 2$ fused to the DNA-binding domain of the yeast Gal4 activator as bait. The C-terminal DE domain of PPAR $\gamma$ encompasses the ligand-binding domain and the liganddependent activation function AF-2. One of the constructs isolated in our yeast two-hybrid screen (clone no. 66) was a cDNA containing an open reading frame of $1488 \mathrm{bp}$. This region corresponds to the C-terminal part of hSAFBl protein (nt 1314-2801 of NM_002967) (Fig. 1A). We then cloned the full-length hSAFB1 cDNA. SAFBl contains a central RNA recognition motif (RRM) and an N-terminal SAF box (also called SAP motif (for SAFA/B, acinus and protein inhibitor of activated signal transducer and activator of transcription), which is a putative DNA-binding domain found in diverse nuclear proteins involved in chromosomal organization (Aravind \& Koonin 2000, Kipp et al. 2000). This protein also contains some Glu/Arg- and Gly-rich regions that may be involved in protein-protein interactions. SAFB1 does not contain any coactivator motif (such as a LXXLL motif, where $\mathrm{L}$ is a leucine and $\mathrm{X}$ any amino acid) or corepressor box.

We then tested the mRNA expression level of SAFB1 in various tissues or cells. RT-PCR analysis shows that SAFB1 is ubiquitously expressed in human tissue (Fig. 1B), and in cell lines such as Caco-2 and 3T3-L1 (data not shown). Additionally, SAFB1 mRNA is already expressed in mouse ES cells (data not shown) and embryos from day 6 postcoitum onward (Fig. 1G). 
A
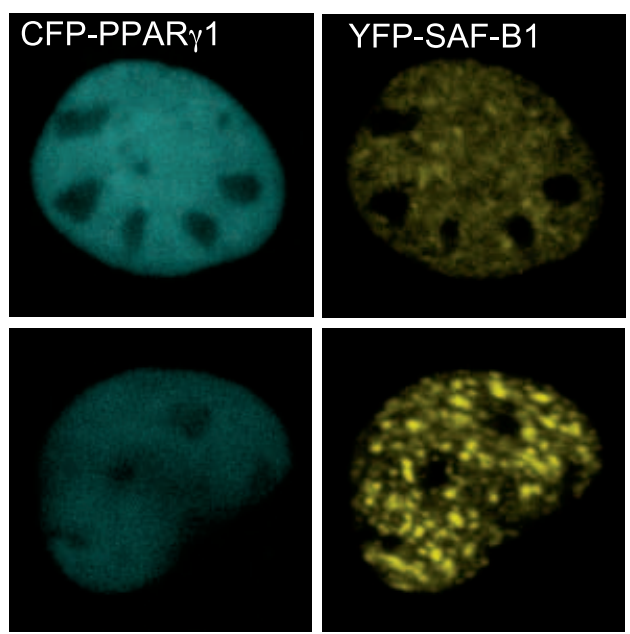
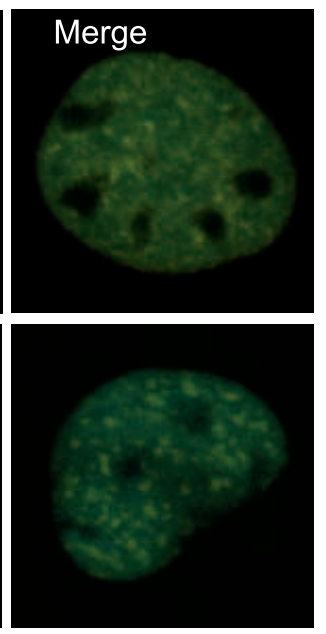

B

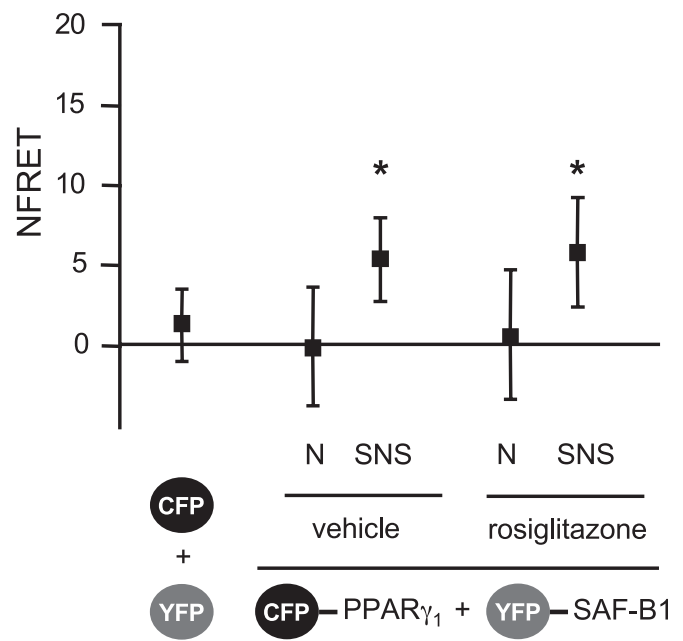

Figure 3 SAFB1 and PPAR $\gamma$ interact in cells. (A) EYFP-SAFB1 and ECFP-mPPAR $\gamma 1$ were expressed in living COS-7 cells and imaged by confocal microscopy. (B) SAFB1 interacts with PPAR $\gamma$ in living cells: EYFP-SAFB1 and ECFP-mPPAR 1 were coexpressed in living COS-7 cells, and their interaction was assessed by FRET either in the nucleoplasm (N) or in subnuclear structures (SNS). As a negative control, FRET was measured in cells expressing ECFP and EYFP alone. FRET was corrected for spectral bleed-throughs and normalized as described in the Materials and methods section. Average normalized FRET (NFRET) values over at least 15 cells are represented. The asterisk denotes $P$ value smaller than 0.01 compared with the negative control, using Student's $t$-test.

Hence, these data extend the previously reported results on SAFB1 expression (Renz \& Fackelmayer 1996).

\section{SAFB1 interacts with PPAR $\gamma$ and other nuclear receptors}

To confirm the interaction between SAFB 1 and PPAR $\gamma$ detected in the yeast two-hybrid screen, we produced GST-fusion proteins comprising full-length coding sequence of SAFB1 downstream of the GST protein. In vitro interaction between GST-SAFB 1 and in vitro translated PPAR $\gamma$ was assayed in pull-down experiments. p300 is a known partner of PPAR $\gamma$ and was used as a positive control. When fused to GST, p300 interacts with human PPAR $\gamma 2$ (hPPAR $\gamma 2$ ) and mouse PPAR $\gamma 1$ $(\mathrm{mPPAR} \gamma \mathrm{l})$ in a ligand-dependent manner, as previously described (Gelman et al. 1999) (Fig. 2A, lanes 5 and $6 ; 11$ and 12). When fused to GST, SAFB1 interacted also with hPPAR $\gamma 2$ and mPPAR $\gamma 1$ (Fig. 2A, lanes 4 and 5; 8 and 9). No interaction was observed between GST alone (negative control) and the two PPARs (Fig. 2A, lanes 2 and 7).

In our yeast two-hybrid screen, we isolated the C-terminal part of SAFB1 as an interacting partner of PPAR $\gamma$ DE domain (C-terminal part). We next mapped the interacting domains between both proteins. Various domains of PPAR $\gamma(\mathrm{AB}, \mathrm{bABC}$ and $\mathrm{DE})$ were fused to GST and incubated with the SAFB1 C-terminus fused to a HA tag. In a GST pull-down assay, both the bABC and DE domains of PPAR $\gamma$ interacted with the SAFB1 construct (Fig. 2B). From this, we can conclude that both the $\mathrm{A} / \mathrm{B}$ and $\mathrm{D} / \mathrm{E}$ domains of PPAR $\gamma$ interact with SAFB 1 (specifically, here, its C-terminal region), as previously shown for the p300 cofactor (Gelman et al. 1999).

We subsequently analyzed the interaction between both proteins in vivo, in living cells, using FRET. First of all, we characterized the cellular localization of SAFB1, using an EYFP-SAFB1 fusion protein expressed alone in COS-7 cells. SAFB1 was exclusively nuclear, was excluded from the nucleolus and formed subnuclear speckles in some but not all transfected cells. Cells expressing EYFP-SAFB1 displayed two different nuclear patterns, one diffuse and one with speckles (Fig. 3A). Importantly, these subnuclear structures did not result from overexpression, as only cells with low expression levels were analyzed and similar structures were also observed with other nuclear receptor cofactors such as CBP/p300, GRIP1 and SRC-1 (our unpublished data; Doucas et al. 1999, Stenoien et al. 2000, Baumann et al. 2001, McManus \& Hendzel 2003, Black et al. 2004). Then, EYFP-SAFB1 was coexpressed with ECFPmPPAR $\gamma 1$, which localized to the nucleus as well, with no sign of enrichment in the subnuclear structures formed by EYFP-SAFB1. When FRET was quantified in the nucleoplasm of cells not harboring subnuclear speckles, the average FRET value was comparable to that of the negative control expressing ECFP and EYFP 
A

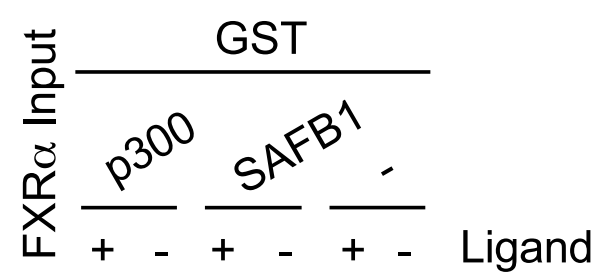

B
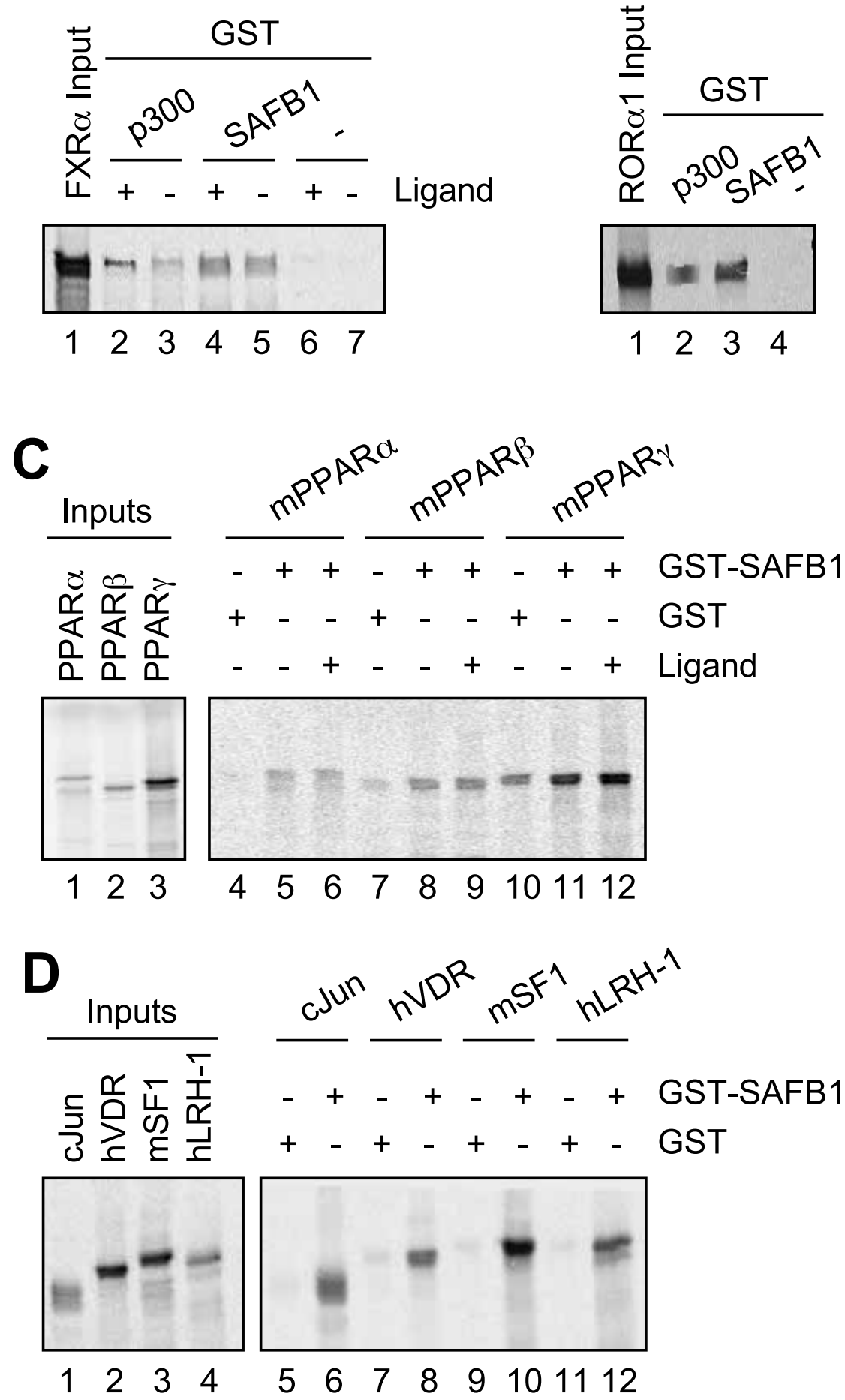

Figure 4 SAFB1 interacts with numerous transcription factors. GST-fusion proteins were incubated with in vitro translated nuclear receptors as well as cJun, eventually in the presence or absence of their respective ligands. (A) FXR $\alpha$, with or without GW4064;

(B) hROR $\alpha 1$; (C) mPPAR $\alpha$, mPPAR $\beta$ and mPPAR $\gamma$, with or without Wy14643, L-165041 or rosiglitazone respectively; (D) hcJun, hVDR, mSF1 and hLRH-1. 

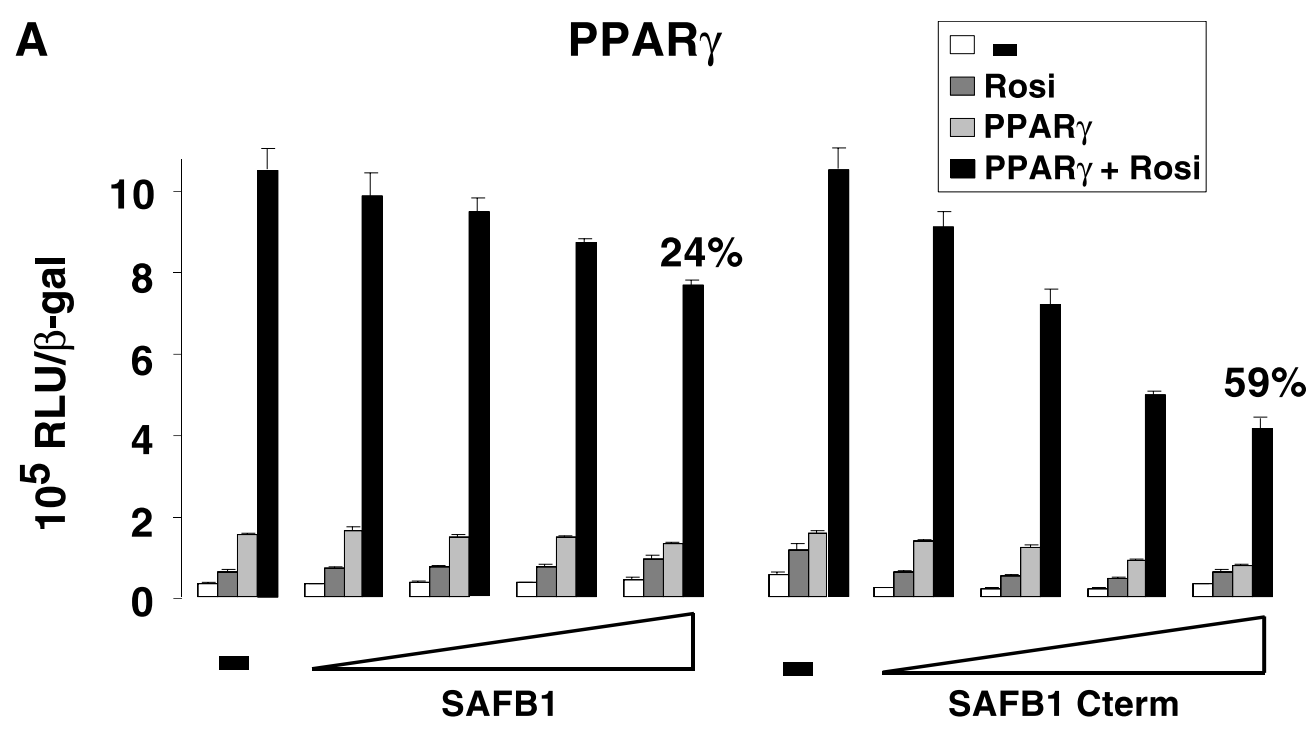

B
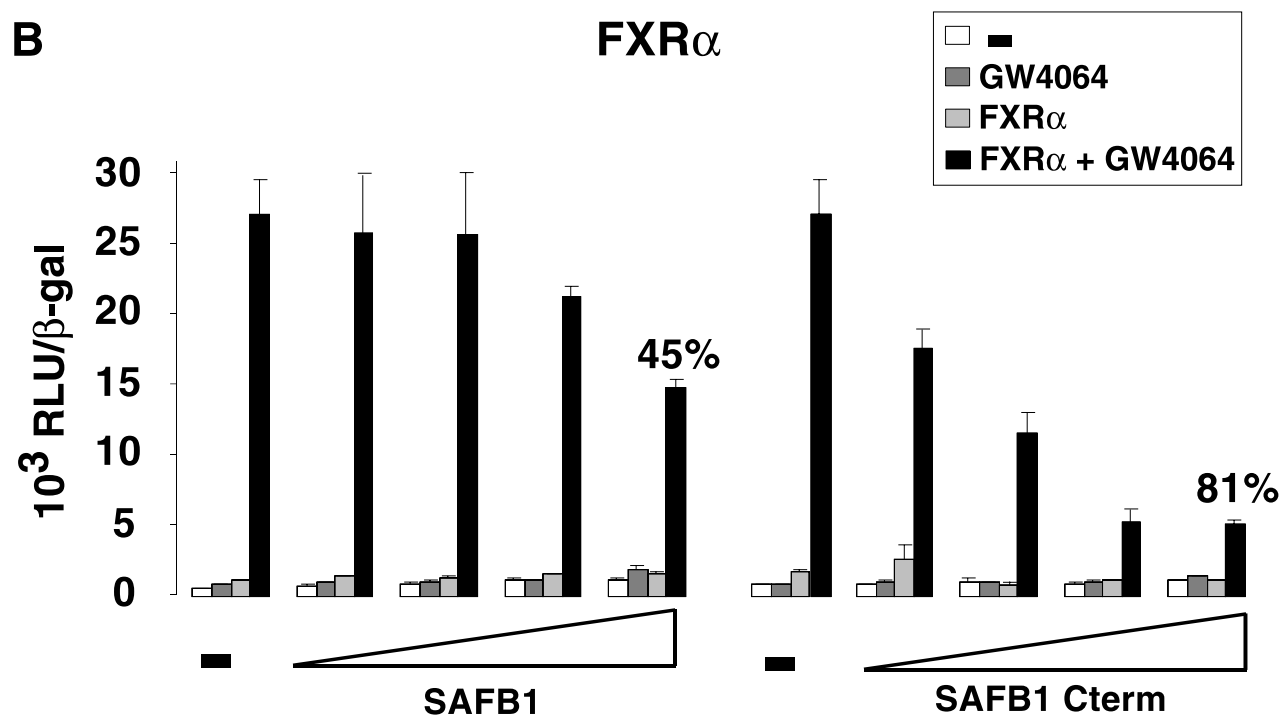

C

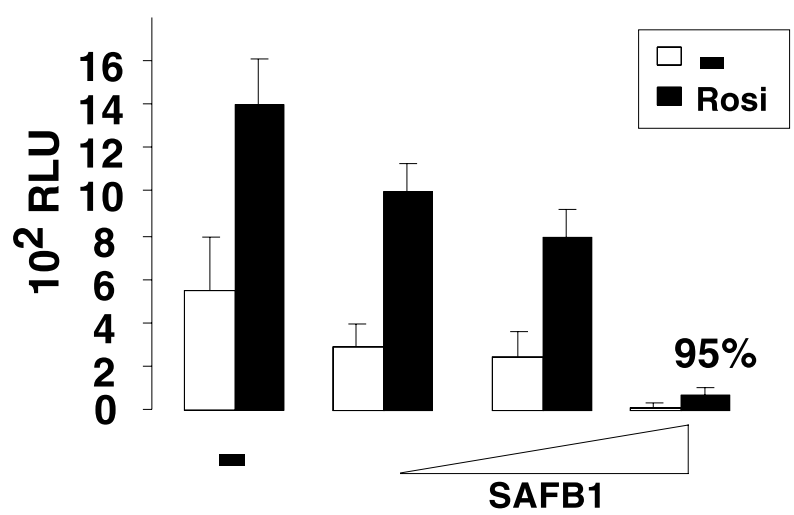


alone (Fig. 3B). However, FRET quantification in the EYFP-SAFB1 speckles revealed a significant interaction between the two fusion proteins, which occurred at similar levels in both the presence and absence of ligand.

The fact that SAFB1 interacts with both ER and PPAR $\gamma$ prompted us to investigate the specificity of the interaction with other nuclear receptors, as well as the nonrelated cJun transcription factor. We first performed GST pull-down assays by incubating GST-SAFB1 or GST-p300 with in vitro translated Farnesoid X receptor (FXR) $\alpha$. We observed a clear interaction between FXR $\alpha$ and GST-SAFB 1 that was ligand-independent (Fig. 4A, lanes 4 and 5), whereas the interaction between FXR $\alpha$ and p300 was ligand-dependent (Fig. 4A, compare lanes 2 and 3), mimicking the mode of interaction of PPAR $\gamma$ with these two cofactors (Fig. 2A). No interaction was observed with GST alone (Fig. 4A, lanes 6 and 7). Furthermore, GST-SAFB1 also interacted with human ROR $\alpha 1$ (hROR $\alpha$ l, Fig. 4B), mouse (m) PPAR $\alpha, \beta$ and $\gamma$ (Fig. $4 \mathrm{C}$ ), the human vitamin $\mathrm{D}$ receptor (hVDR), the mouse steroidogenic factor $1(\mathrm{mSF} 1)$ and the human liver receptor homolog 1 (hLRH-1) (Fig. 4D). Again, none of these receptors interacted with GST alone. Interestingly, SAFB 1 also interacted with the human cJun (Fig. 4D). We hence conclude that SAFB1 interacts promiscuously with various nuclear receptors, although the strength of interaction varies with the receptor tested. Indeed, SF1, LRH1 and cJun interact on average four times better than $\operatorname{PPAR} \alpha, \operatorname{PPAR} \beta, \operatorname{PPAR} \gamma$ and VDR.

\section{SAFB1 inhibits nuclear receptor transcriptional activity}

SAFB1 has been described as a protein repressing ER $\alpha$ transactivation (Oesterreich et al. 2000), and hence we tested the possibility that SAFB1 could also act as a corepressor for other nuclear receptors. COS-1 cells were cotransfected with reporter constructs under the control of PPAR or FXR responsive elements (RE), together with expression vectors for PPAR $\gamma$ or FXR $\alpha$ and increasing amounts of an expression vector for
SAFB1 or the corresponding empty vector, in the presence or absence of ligand. PPAR $\gamma$ transcriptional activity is stimulated in the presence of rosiglitazone, and increasing concentrations of SAFB 1 inhibit PPAR $\gamma$ activation by up to $24 \%$ (Fig. $5 \mathrm{~A}$, left panel). When a similar experiment was performed with the $\mathrm{C}$-terminal part of SAFB1, the inhibition of PPAR $\gamma$ activity reached $59 \%$ (Fig. 5A, right panel). SAFB1 repressed the transcriptional activity of FXR $\alpha$ as well in a dosedependent manner (Fig. 5B). This inhibition was more pronounced than for PPAR $\gamma(45 \%$ vs 24\%). Again, the SAFB1 C-terminal domain was a better repressor (up to $81 \%$ of inhibition) than the full-length SAFB 1 protein. It is noteworthy that SAFB1 did not affect the basal activity of the TK-Luc reporter backbone (data not shown), indicating that SAFB1-mediated modulation of nuclear receptor activity is specific for the nuclear receptors tested and does not correspond to a general repressive effect on transcription.

The repressive action of SAFB 1 on PPAR $\gamma$ transcriptional activity was then tested in another promoter context. HEK293 cells were transfected with an expression vector for a fusion protein comprising the DNA-binding domain of Gal4 and the D/E domain of PPAR $\gamma$, together with a reporter construct comprising five Gal4 responsive elements cloned upstream of a TK promoter and driving the expression of the luciferase cDNA (Fig. 5C). Cotransfection of increasing amounts of an expression vector for SAFB1 inhibited Gal4PPAR $\gamma \mathrm{D} / \mathrm{E}$ transcriptional activity by up to $95 \%$.

These data show that SAFB1 decreases PPAR $\gamma$, FXR $\alpha$ and Gal4-PPAR $\gamma \mathrm{D} / \mathrm{E}$ transcriptional activity and that the extent of inhibition varies according to the receptor and the promoter tested, reflecting most probably a specific action rather than a common effect of the basic transcription machinery.

Transcriptional repression often involves the presence of proteins called histone deacetylases (HDACs). We thus assessed the action of HDAG inhibitors on SAFB1-mediated transcriptional repression. COS-1 cells were cotransfected as previously, in the presence or absence of various HDAC inhibitors. Each of these

\footnotetext{
Figure 5 SAFB1 represses PPAR $\gamma 2$ and FXR $\alpha$ transcriptional activities. (A and B) SAFB1 inhibits the ligand-dependent and -independent transcriptional activities of PPAR $\gamma 2(\mathrm{~A})$ and FXR $\alpha(\mathrm{B})$. COS-1 cells were transfected with a PPAR (A) or a FXR (B) reporter construct (PPRE-TK-Luc or FXR-TK-Luc respectively), an expression vector for PPAR $\gamma$ (18 $\mathrm{ng}$ ) or for FXR $\alpha$ (20 $\mathrm{ng}$ ), an expression vector for $\mathrm{RXR} \alpha$ (18 $\mathrm{ng}$ with PPAR $\gamma$ or $2 \mathrm{ng}$ with $\mathrm{FXR} \alpha$ respectively), and increasing amounts of an expression vector for full-length SAFB1, for the truncated SAFB1 C-terminal protein $(10,20,50$ or $100 \mathrm{ng} /$ well) or with the corresponding empty vectors $(-)$. The presence of agonist $\left(10^{-7} \mathrm{M}\right.$ rosiglitazone for PPAR or $10^{-7} \mathrm{M}$ GW4064 for FXR) or vehicle (dimethyl sulfoxide (-)) is indicated. The numbers above the shaded bars indicate the percentage of reduction of normalized luciferase activity compared with the same condition in the absence of SAFB1. RLU: relative luciferase units; $\beta$-gal: $\beta$-galactosidase activity. (C) SAFB1 inhibits the transcriptional activity of a Gal4 DBD-PPAR $\gamma 2$ chimera. The same experiments were conducted as in A and B but with an expression vector for the DNA-binding domain of Gal4 fused to the ligand-binding domain of PPAR $\gamma$ (pcDNA3-BDGal4-PPAR $\gamma$ DE, $18 \mathrm{ng} /$ well) together with a reporter construct where the transcription of the luciferase gene is driven by a TK promoter and five Gal4-binding elements (pGL3-(GAL)5-TK-Luc, $90 \mathrm{ng} /$ well) and with increasing amounts of an expression vector for full-length SAFB1 $(18,72$ or $216 \mathrm{ng} /$ well) or with the corresponding empty vector $(-)$. Cells were grown for $24 \mathrm{~h}$ in the presence or absence of $10^{-6} \mathrm{M}$ rosiglitazone.
} 
inhibitors affected SAFB1 action very differently, depending also on the receptor tested (Fig. 6). Neither trichostatin A (TSA), nicotinamide nor suberoylanilide hydroxamic acid (SAHA) had any effect on the repression of PPAR $\gamma$ activity by SAFB1, whereas MS-275 relieved the action of SAFB1, but not that of its C-terminus. TSA reversed very slightly the action of SAFB on FXR, whereas SAHA, nicotinamide and MS-275 exacerbated it. We did not find any synergistic effect when inhibitors of class I/II (TSA, MS-275 or SAHA) and of class III (nicotinamide) were added together (data not shown). It is also noteworthy that these inhibitors had no effect on the activity of the CMV- $\beta$ Gal control (data not shown).

\section{SAFB1 expression is decreased during 3T3-L1 differentiation into adipocytes, and Caco-2 differentiation into enterocytes}

SAFB 1 was cloned from a human adipose tissue library on the basis of its interaction with PPAR $\gamma$ in a yeast two-hybrid system, an interaction further confirmed by pull-down and FRET experiments. We therefore hypothesized that SAFB1 may play a role in adipocyte differentiation. We first monitored the expression level of SAFB1 during 3T3-L1 adipocyte differentiation. The preadipocyte 3T3-L1 cell line can differentiate into adipocytes when treated with an adipocyte differentiation mix for 2 days and then with insulin alone. After 12 days, such 3T3-L1 cells display a differentiated adipocyte-like phenotype, as evidenced by the accumulation of lipid droplets in their cytoplasm and revealed by Oil red $\mathrm{O}$ staining (data not shown). Quantitative real-time PCR experiments showed that the highest level of SAFB1 mRNA expression is obtained immediately after the induction of the differentiation (days $0-1$ of the adipocyte differentiation process) (Fig. 7A, upper panel). SAFB1 mRNA expression level then returns to basal levels. At the protein level, a rapid decrease of SAFB1 expression was observed during the first 2 days of differentiation (Fig. 7B, upper panel). As previously reported, PPAR $\gamma 2$ expression level increased later during 3T3-L1 differentiation (mRNA level, Fig. 7A, upper panel); protein level (Fig. 7B, middle panel). Hence, SAFB 1 and PPAR $\gamma$ protein expression followed an opposite expression pattern during 3T3-L1 differentiation (Fig. 7B).

SAFB 1 has been shown to have antiproliferative properties (Townson et al. 2000). It is hence tempting to speculate that the high expression of SAFB1 at the beginning of adipocyte differentiation contributes to the onset of differentiation. To validate experimentally such an antiproliferative role of SAFB1, we set out to change the basal expression level of SAFB1 in 3T3-L1 cells. For stable overexpression of SAFB1, we infected cells with a retrovirus encoding SAFB1 or with an empty control retrovirus. However, we were unable to obtain a stable cell line overexpressing SAFB1, whereas clones were obtained for the cell line infected with the control retrovirus. This strongly suggests that SAFB1 inhibits 3T3-L1 cell proliferation, as was demonstrated for other cell lines. Moreover, our attempt to decrease SAFB1 expression in cells by the RNA interference technique led to only very modest reductions of SAFB1 levels, not sufficient to carry out proliferation and differentiation analyses in this context.

Since we suspected SAFB1 to have a general action in cell proliferation and differentiation, we also monitored SAFB1 protein levels in differentiating Caco-2 cells. When grown for 21 days after confluence, these cells acquire an enterocyte phenotype). Caco-2 cells express the highest level of SAFB1 protein early during the differentiation process at day 7 (Fig. 7C), these levels decreasing thereafter. Together with the data obtained in adipocytes, these results suggest that SAFB 1 might be involved in cell decisions leading to differentiation.

\section{Discussion}

In an attempt to isolate new coregulators of PPAR $\gamma$ activity, we identified, cloned and characterized SAFB1, a protein also known as HET or HAP. PPAR $\gamma$ and $\mathrm{SAFB} 1$ interact both in vitro and in vivo. Other nuclear receptors, such as FXR $\alpha$, ROR $\alpha 1, \operatorname{PPAR} \alpha, \operatorname{PPAR} \beta$, VDR, SF1 and LRH-1 are also shown here to interact with SAFB1. This interaction between the nuclear receptors and SAFB1 was ligand-independent, as previously reported for the interaction between ER $\alpha$ and SAFB1 (Oesterreich et al. 2000). The promiscuous interaction of SAFB1 with all nuclear receptors tested in this study and with ER, as well as with the unrelated cJun transcription factor, raises the question of the specificity of the interaction. Such a promiscuous mode of action has been already reported for the p300/CBP and SRC-1 coactivators. SAFB1 is a big protein of 915 residues that may offer numerous docking sites for other proteins. It will be interesting in the future to map precisely the domains within SAFB1 that are involved in the recruitment of these different transcription factors. It is noteworthy that we found a very broad expression pattern for SAFB1, supporting the idea that SAFB1 should be able to interact with numerous cellular components in different cellular contexts. As reported for $\mathrm{ER} \alpha$, we demonstrated here that SAFB1 inhibited the transcriptional activity of PPAR $\gamma$ and $\operatorname{FXR} \alpha$, suggesting that SAFB1 is a genuine nuclear receptor corepressor. We demonstrated that the SAFB1 G-terminus is a much more potent repressor of transcriptional activity than the full-length protein. This is consistent with recent data showing that the repression 

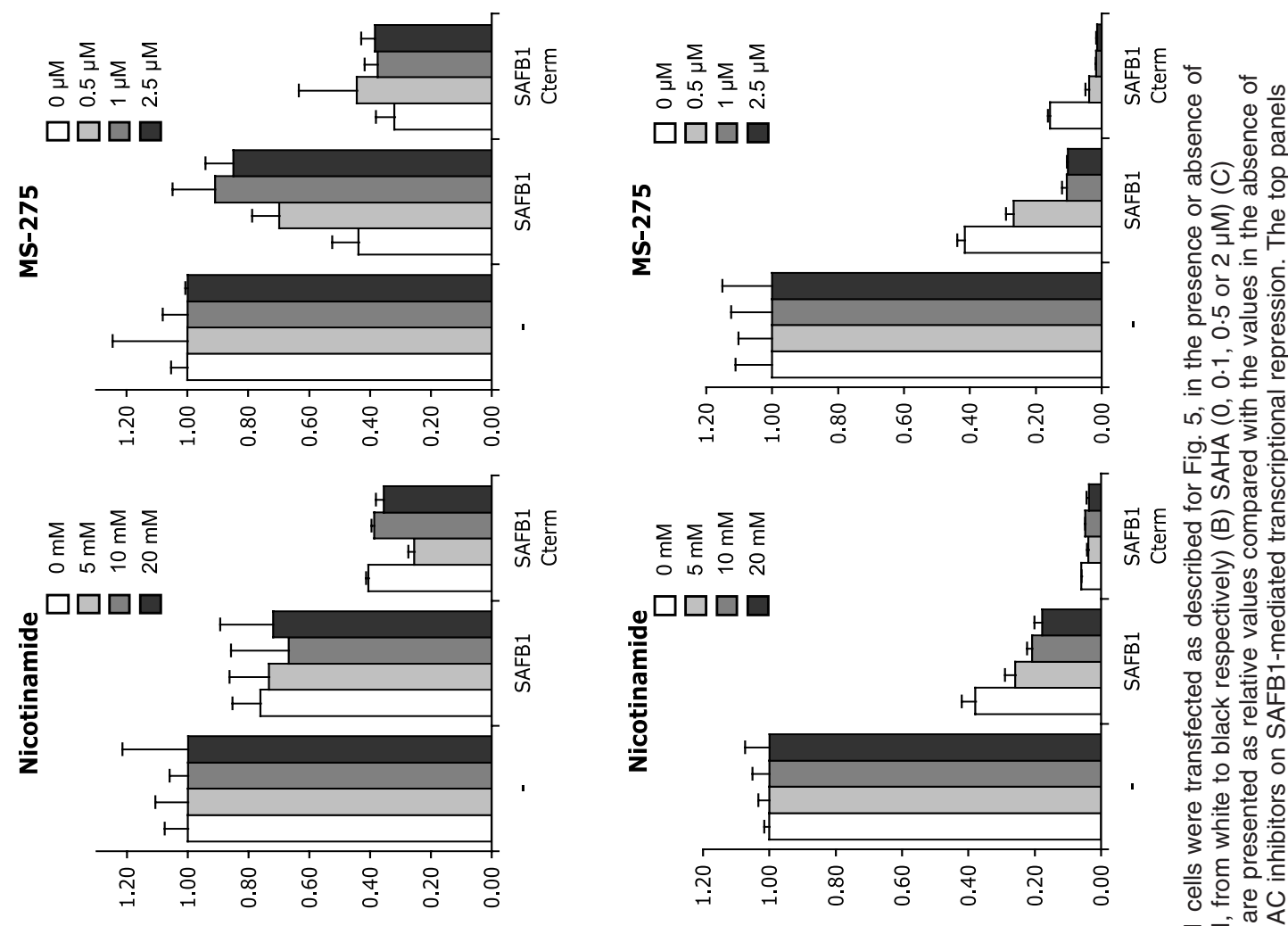

- $\stackrel{0}{\sigma} 0$

ज

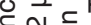

ه

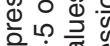

过

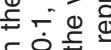

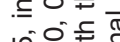

ơ

证兵安

市

을 를

更

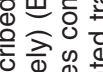

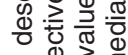

is 8

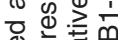

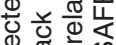

क⿺辶一兀)

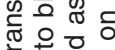

$=0$

过

क ह 흘

\% 은

的要垔
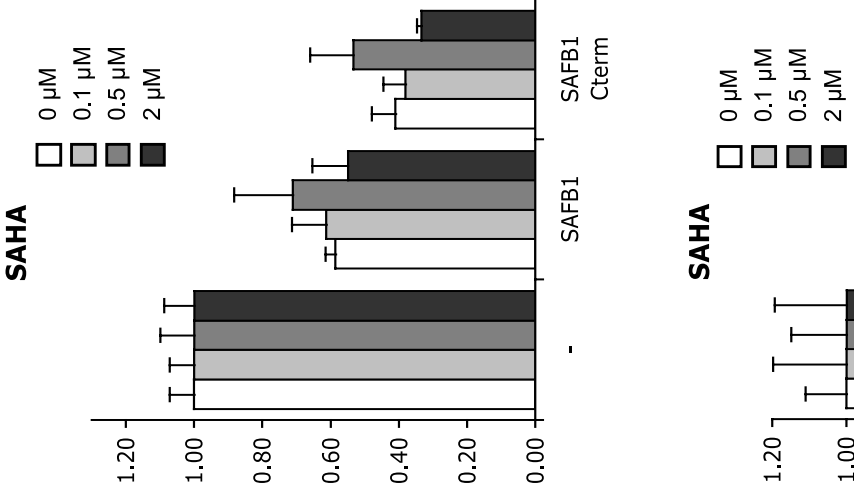

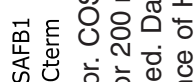

응응

엉응 웜

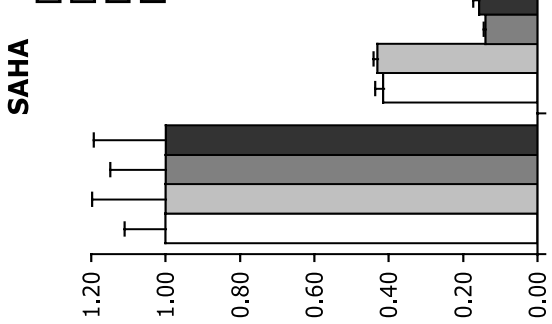

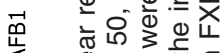

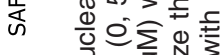

屁约

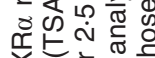

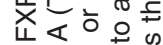

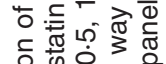

क

흔은 능흥

원 숭웡

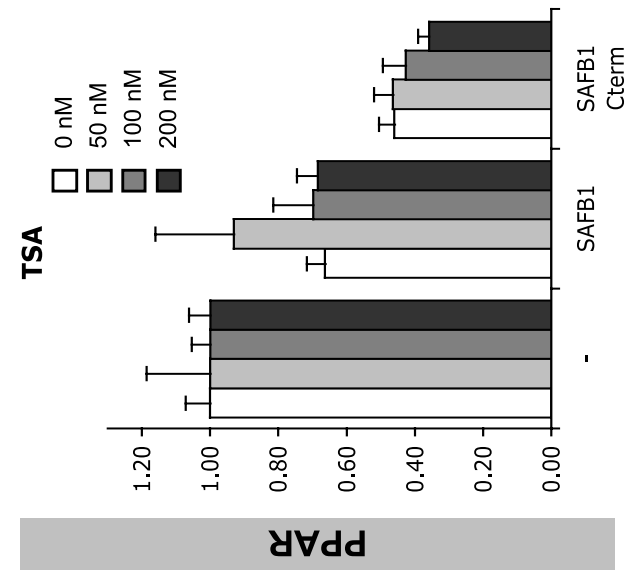

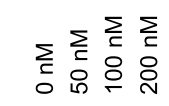

ㅁㅁ밈
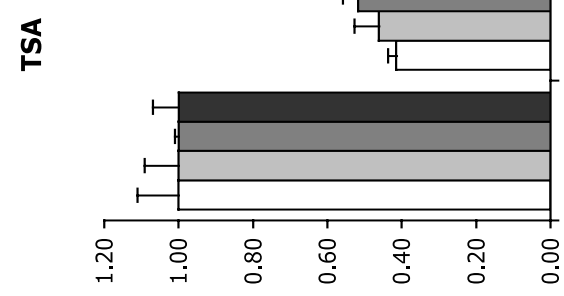

QXJ

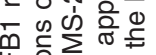

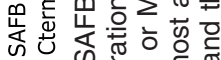
论

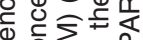

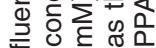

원 3

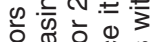

을 잉으는 응

S

잏워

政

至

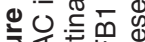

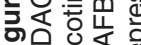




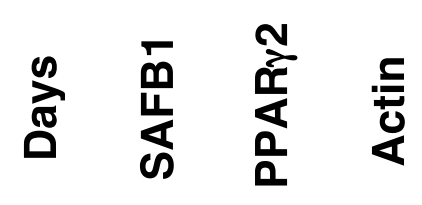

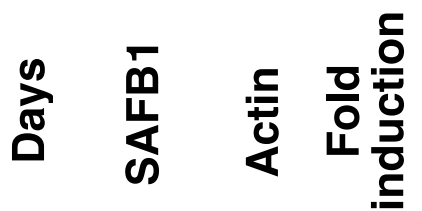
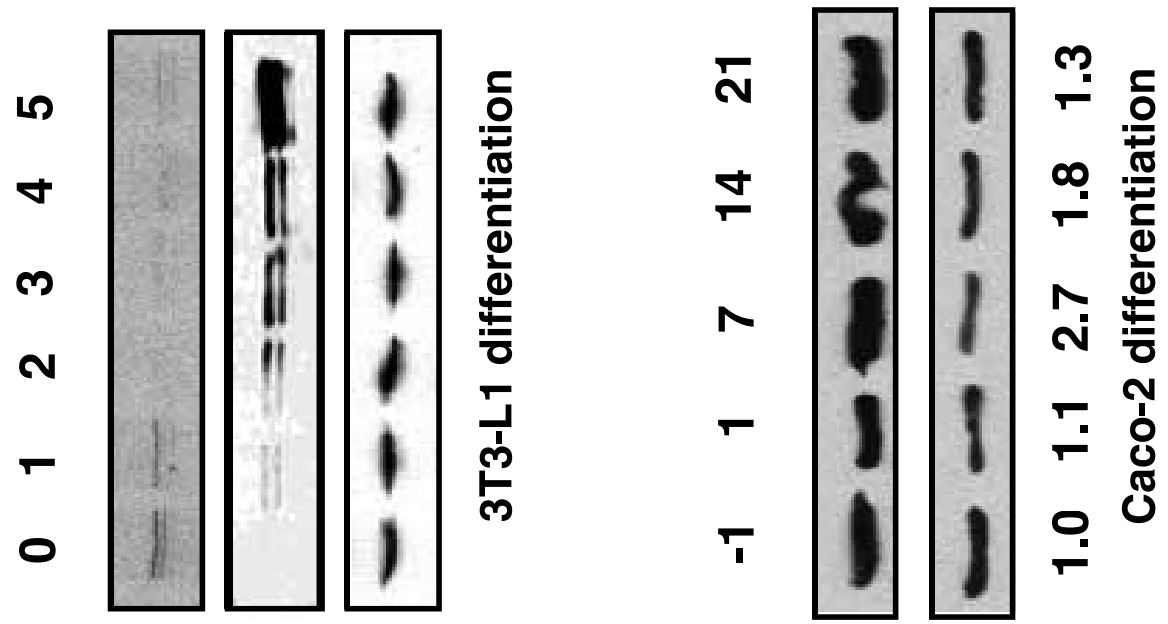

$\mathbf{m}$

0

$\left(-{ }^{g} \mathrm{OL}\right)$ dəqunu

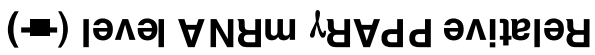

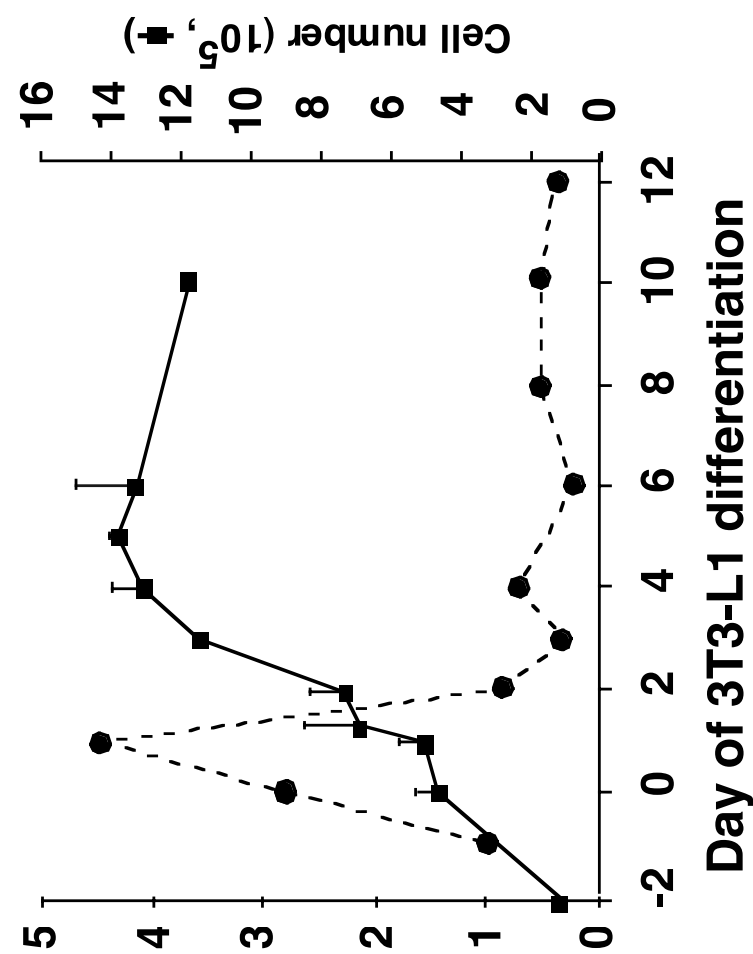

品

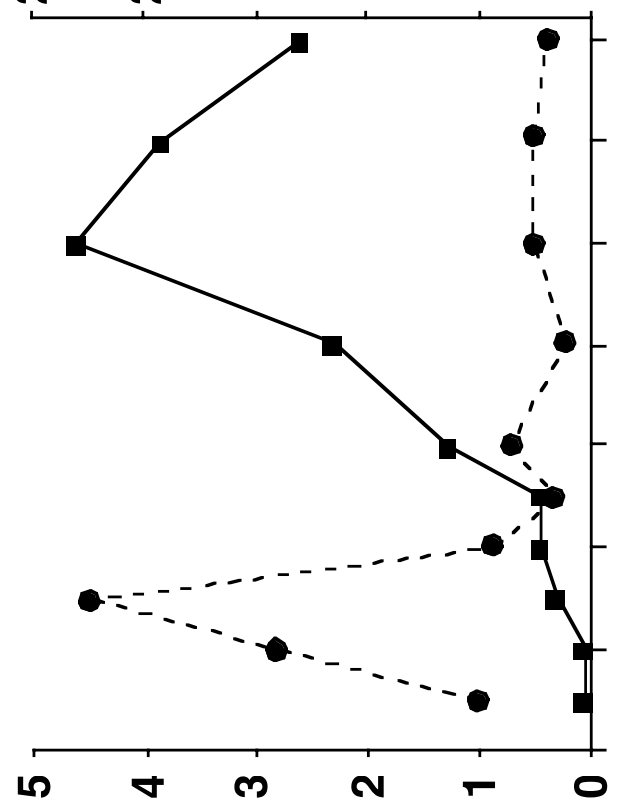

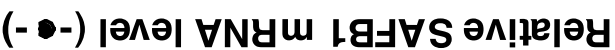

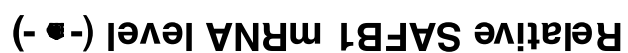


domain of SAFB1 resides in the C-terminal part of the protein (Townson et al. 2004). Corepressors of nuclear receptors often possess HDAC activity or interact with HDACs. We show here that SAFB action is specifically affected by four different HDAC inhibitors, depending on the receptor tested (FXR or PPAR). Although these results may appear confusing at first sight, they most probably reflect the recruitment of different types of HDACs by each receptor, as well as some specific interplay between HDACs on the one hand and promoters and ligands on the other hand, as recently exemplified with the estrogen receptor (ER), whose action is differently modulated by HDAC inhibitors, depending upon the cell line and the ligand tested (Margueron et al. 2004). It is also possible that these compounds have some side effects and modulate other cellular components which indirectly affect the transcription of the reporter construct. However, these inhibitors had no effect on the activity of the CMV- $\beta$ Gal control, ruling out some general and unspecific effects on basal transcription.

PPAR $\gamma$ activity in adipocytes is modulated by a number of coregulators. More particularly, the CREBbinding protein (Yamauchi et al. 2002), the steroid receptor coactivator-1/transcriptional intermediary factor 2 (Picard et al. 2002), the PPAR $\gamma$ coactivator-1 (Puigserver et al. 1998), the receptor interacting protein 140 (Leonardsson et al. 2004), and the thyroid hormone receptor-associated protein 220 (Ge et al. 2002) have all been shown to have an impact on adipocyte differentiation. Hence, we hypothesized that SAFB1, which was isolated from an adipose tissue cDNA library, could also affect adipocyte differentiation. Consistent with such a role, we found that SAFB1 expression level in 3T3-L1 cells changed during the initial phases of differentiation into adipocytes. SAFB1 expression levels are high in preadipocytes and decrease rapidly upon differentiation. This is consistent with the hypothesis that high levels of SAFB1 prevent 3T3-L1 cell proliferation. An inhibitory effect of SAFB1 on cell proliferation was also reported for NIH3T3 and HEK293 cells as well as some breast cancer cell lines (Townson et al. 2000).

In view of the potential of SAFB1 to repress cell proliferation and of our observations of regulated expression of SAFB1 during adipogenesis, one hypothesis merits particular attention. The level of expression of SAFB1 during cell cycle has been correlated to a role of this protein in transcription control (Townson et al. 2000). Indeed, when cells are in the G2/M phase of the cell cycle, SAFB1 might be involved in the packaging of chromatin for mitosis, hence inhibiting transcription during the clonal expansion phase. SAFB1 expression could, however, in view of its effects on cell proliferation, subsequently indicate the end of the clonal expansion phase and limit the length of this phase. SAFB 1 might thus be a factor both facilitating the entry and triggering the subsequent exit from the clonal expansion phase and consequently permitting progression of cells through the initial phases of adipogenesis. Through inhibition of cell proliferation, SAFB1 would thus set the scene for appropriate differentiation.

SAFB1 is a S/MAR-binding protein (Renz \& Fackelmayer 1996), and, as such, connects chromatin to the nuclear matrix. SAFB1 binds to the $\mathrm{C}$-terminal domain of RNA Pol II and to certain splicing factors as well (Nayler et al. 1998) and could thereby affect the subcellular distribution of factors involved in transcription and RNA processing. SAFB 1 might therefore act as an architectural factor that attracts nuclear receptors to the nuclear matrix and influences their effect on transcription and RNA processing.

In summary, we report here that SAFB 1 interacts promiscuously with nuclear hormone receptors, and inhibits their transcriptional activities. SAFB1 expression decreases at the beginning of adipocyte differentiation and is modulated along enterocyte differentiation, suggesting a role for this factor in cell proliferation and differentiation. Finally, we may speculate that SAFB1 may influence many other biologic processes, such as metabolic homeostasis, whose coordination depends on several nuclear receptor activities.

\section{Acknowledgements}

We thank the Auwerx Laboratory, V Giguere, S Green, P Grimaldi, R Heyman, S Kato, D Mangelsdorf, P Sassone-Corsi, G Zhou, and the common services of the institute for their valuable help or gifts of material. Grants from Centre National de la Recherche Scientifique, Institut National de la Santé et de la Recherche Médicale, Hôpitaux Universitaires de Strasbourg, Association pour la Recherche contre le Cancer, Fondation pour la Recherche Médicale, La Ligue Contre le Cancer, the National Institutes of Health, European Community RTD programs, the Swiss National Research Project 50, the Swiss National Science Foundation, and the État de Vaud supported this work.

\section{Funding}

The authors declare that there is no conflict of interest that would prejudice the impartiality of the research reported.

\section{References}

Arao Y, Kuriyama R, Kayama F \& Kato S 2000 A nuclear matrix-associated factor, $\mathrm{SAF}-\mathrm{B}$, interacts with specific isoforms of AUF1/hnRNP D. Archives in Biochemistry and Biophysics 380 $228-236$ 
Aravind L \& Koonin EV 2000 SAP - a putative DNA-binding motif involved in chromosomal organization. Trends in Biochemical Science $25112-114$.

Auwerx J 1999 PPAR $\gamma$, the ultimate thrifty gene. Diabetologia 42 1033-1049.

Bauer UM, Daujat S, Nielsen SJ, Nightingale K \& Kouzarides T 2002 Methylation at arginine 17 of histone H3 is linked to gene activation. EMBO Reports 3 39-44.

Baumann CT, Ma H, Wolford R, Reyes JC, Maruvada P, Lim C, Yen PM, Stallcup MR \& Hager GL 2001 The glucocorticoid receptor interacting protein 1 (GRIP1) localizes in discrete nuclear foci that associate with ND10 bodies and are enriched in components of the 26S proteasome. Molecular Endocrinology 15 485-500.

Becker PB \& Horz W 2002 ATP-dependent nucleosome remodeling. Annual Reviewes in Biochemistry 71 247-273.

Black BE, Vitto MJ, Gioeli D, Spencer A, Afshar N, Conaway MR, Weber MJ \& Paschal BM 2004 Transient, ligand-dependent arrest of the androgen receptor in sub-nuclear foci alters phosphorylation and co-activator interactions. Molecular Endocrinology 18834.

Chen D, Ma H, Hong H, Koh SS, Huang SM, Schurter BT, Aswad DW \& Stallcup MR 1999 Regulation of transcription by a protein methyltransferase. Science $2842174-2177$.

Chomczynski P \& Sacchi N 1987 Single step method for RNA isolation by acid guanidinium-thiocyanate-phenol-chloroform extraction. Analytical Biochemistry 162 156-159.

Cock TA, Houten SM \& Auwerx J 2004 Peroxisome proliferator-activated receptor-gamma: too much of a good thing causes harm. EMBO Reports 5 142-147.

Debril MB, Renaud JP, Fajas L \& Auwerx J 2001 The pleiotropic functions of peroxisome proliferator-activated receptor gamma. Fournal of Molecular Medicine 79 30-47.

Debril MB, Gelman L, Fayard E, Annicotte JS, Rocchi S \& Auwerx J 2004 Transcription factors and nuclear receptors interact with the SWI/SNF complex through the BAF60c subunit. Fournal of Biological Chemistry 279 16677-16686.

Doucas V, Tini M, Egan DA \& Evans RM 1999 Modulation of CREB binding protein function by the promyelocytic (PML) oncoprotein suggests a role for nuclear bodies in hormone signaling. PNAS $962627-2632$.

Feige JN, Sage D, Wahli W, Desvergne B \& Gelman L 2005 PixFRET, an image J plug-in for FRET calculation that can accomodate variations in spectral bleed-throughs. Microscopic Research Techniques 68 51-58.

Fajas L, Egler V, Reiter R, Hansen J, Kristiansen K, Debril MB, Miard S \& Auwerx J 2002 The retinoblastoma-histone deacetylase 3 complex inhibits PPAR $\gamma$ and adipocyte differentiation. Developmental Cell 3 903-910.

Fayard E, Schoonjans K, Annicotte JS \& Auwerx J 2003 Liver receptor homolog 1 controls the expression of carboxyl ester lipase. Fournal of Biological Chemistry 278 35725-35731.

Ge K, Guermah M, Yuan CX, Ito M, Wallberg AE, Spiegelman BM \& Roeder RG 2002 Transcription coactivator TRAP220 is required for PPAR gamma 2-stimulated adipogenesis. Nature $\mathbf{4 1 7}$ 563-567.

Gelman L, Zhou G, Fajas L, Raspe E, Fruchart JC \& Auwerx J 1999 p300 interacts with the N- and C- terminal part of PPAR $\gamma 2$ in a ligand-independent and -dependent manner respectively. Fournal of Biological Chemistry 274 7681-7688.

Horn PJ \& Peterson CL 2002 Molecular biology. Chromatin higher order folding - wrapping up transcription. Science 297 1824-1827.

Kipp M, Gohring F, Ostendorp T, van Drunen CM, van Driel R, Przybylski M \& Fackelmayer FO 2000 SAF-Box, a conserved protein domain that specifically recognizes scaffold attachment region DNA. Molecular and Cellular Biology 20 7480-7489.

Leonardsson G, Steel JH, Christian M, Pocock V, Milligan S, Bell J, So PW, Medina-Gomez G, Vidal-Puig A, White R et al. 2004
Nuclear receptor corespressor RIP140 regulates fat accumulation. PNAS 101 8437-8442.

Margueron R, Duong V, Bonnet S, Escande A, Vignon F, Balaguer P \& Cavailles V 2004 Histone deacetylase inhibition and estrogen receptor alpha levels modulate the transcriptional activity of partial antiestrogens. Fournal of Molecular Endocrinology 32 583-594.

McManus KJ \& Hendzel MJ 2003 Quantitative analysis of CBPand P300-induced histone acetylations in vivo using native chromatin. Molecular and Cellular Biology 23 7611-7627.

Nayler O, Stratling W, Bourquin JP, Stagljar I, Lindemann L, Jasper H, Hartmann AM, Fackelmayer FO, Ullrich A \& Stamm S 1998 SAF-B protein couples transcription and pre-mRNA splicing to SAR/MAR elements. Nucleic Acids Research 26 3542-3549.

Neely KE \& Workman JL 2002 The complexity of chromatin remodeling and its links to cancer. Biochimica et Biophysica Acta $160319-29$

Oesterreich S 2003 Scaffold attachment factors SAFB1 and SAFB2: innocent bystanders or critical players in breast tumorigenesis? Fournal of Cell Biochemistry 90 653-661.

Oesterreich S, Lee AV, Sullivan TM, Samuel SK, Davie JR \& Fuqua SA 1997 Novel nuclear matrix protein HET binds to and influences activity of the HSP27 promoter in human breast cancer cells. Fournal of Cell Biochemistry 67 275-286.

Oesterreich S, Zhang Q Hopp T, Fuqua SA, Michaelis M, Zhao HH, Davie JR, Osborne CK \& Lee AV 2000 Tamoxifen-bound estrogen receptor (ER) strongly interacts with the nuclear matrix protein HET/SAF-B, a novel inhibitor of ER-mediated transactivation. Molecular Endocrinology 14 369-381.

Picard F, Gehin M, Annicotte JS, Rocchi S, Champy MF, O'Malley B, Chambon P \& Auwerx J 2002 SRG-1 and TIF2 control energy balance between white and brown adipose tissues. Cell 111 931-941.

Puigserver P, Wu Z, Park CW, Graves R, Wright M \& Spiegelman BM 1998 A cold-inducible coactivator of nuclear receptors linked to adaptive thermogenesis. Cell $\mathbf{9 2} 829-839$.

Renz A \& Fackelmayer FO 1996 Purification and molecular cloning of the scaffold attachment factor B (SAF-B), a novel human nuclear protein that specifically binds to S/MAR- DNA. Nucleic Acids Research 24 843-849.

Robyr D, Wolffe AP \& Wahli W 2000 Nuclear hormone receptor coregulators in action: diversity for shared tasks. Molecular Endocrinology 14 329-347.

Rosen ED \& Spiegelman BM 2001 PPARgamma: a nuclear regulator of metabolism, differentiation, and cell growth. Fournal of Biological Chemistry 276 37731-37734.

Roth SY, Denu JM \& Allis CD 2001 Histone acetyltransferases. Annual Reviewes of Biochemistry 70 81-120.

Schoonjans K \& Auwerx J 2000 Thiazolidinediones: an update. Lancet 355 1008-1010.

Schoonjans K, Martin G, Staels B \& Auwerx J 1997 Peroxisome proliferator-activated receptors, orphans with ligands and functions. Current Opinion in Lipidology 8 159-166.

Stenoien DL, Mancini MG, Patel K, Allegretto EA, Smith CL \& Mancini MA 2000 Subnuclear trafficking of estrogen receptor-alpha and steroid receptor coactivator-1. Molecular Endocrinology 14 518-534.

Sudarsanam P \& Winston F 2000 The Swi/Snf familynucleosome-remodeling complexes and transcriptional control. Trends in Genetics $\mathbf{1 6} 345-351$.

Townson SM, Sullivan T, Zhang Q Clark GM, Osborne CK, Lee AV \& Oesterreich S 2000 HET/SAF-B overexpression causes growth arrest and multinuclearity and is associated with aneuploidy in human breast cancer. Clinical Cancer Research 6 3788-3796.

Townson SM, Dobrzycka KM, Lee AV, Air M, Deng W, Kang K, Jiang S, Kioka N, Michaelis K \& Oesterreich S 2003 SAFB2, a new scaffold attachment factor homolog and estrogen receptor corepressor. Fournal of Biological Chemistry 278 20059-20068. 
Townson SM, Kang K, Lee AV \& Oesterreich S 2004 Structure-function analysis of the estrogen receptor alpha corepressor scaffold attachment factor-B 1: identification of a potent transcriptional repression domain. Fournal of Biological Chemistry $27926074-26081$.

Urnov FD \& Wolffe AP 2001 A necessary good: nuclear hormone receptors and their chromatin templates. Molecular Endocrinology 15 $1-16$.

Wang H, Huang ZQ, Xia L, Feng Q Erdjument-Bromage H, Strahl BD, Briggs SD, Allis CD, Wong J, Tempst P et al. 2001 Methylation of histone $\mathrm{H} 4$ at arginine 3 facilitating transcriptional activation by nuclear hormone receptor. Science 293 853-857.

Weighardt F, Cobianchi F, Cartegni L, Chiodi I, Villa A, Riva S \& Biamonti G 1999 A novel hnRNP protein (HAP/SAF-B) enters a subset of hnRNP complexes and relocates in nuclear granules in response to heat shock. Fournal of Cell Science 112 (Pt 10) 1465-1476.
Willson TM, Lambert MH \& Kliewer SA 2001 Peroxisome proliferator-activated receptorg and metabolic disease. Annual Reviews in Biochemistry 70 341-367.

Xia Z \& Liu Y 2001 Reliable and global measurement of fluorescence resonance energy transfer using fluorescence microscopes. Biophysics fournal 81 2395-2402.

Yamauchi T, Oike Y, Kamon J, Waki H, Komeda K, Tsuchida A, Date Y, Li MX, Miki H, Akanuma Y et al. 2002 Increased insulin sensitivity despite lipodystrophy in Crebbp heterozygous mice. Nature Genetics 30 221-226.

Received 2 August 2005

Accepted 30 August 2005

Made available online as an Accepted Preprint 4 October 2005 